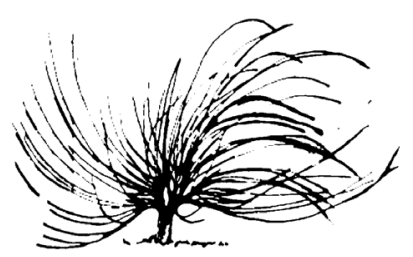

\title{
Pedagogía de la música en la educación superior costarricense: Un acercamiento crítico hacia la descolonización de los procesos de enseñanza-aprendizaje
}

\author{
Juan Carlos Espinoza Mora ${ }^{1}$ \\ Universidad Nacional \\ Costa Rica \\ juancaem_27@hotmail.com
}

\begin{abstract}
Resumen
Este trabajo pretende generar una revisión crítica del modelo pedagógico que ha imperado en Costa Rica para la educación musical, especialmente, a partir de la denominada "reforma cultural" de inicios de la década de 1970. En la búsqueda de encontrar modelos educativos alternativos, este trabajo se plantea partir de la epistemología de una pedagogía crítica que intente desarrollar una propuesta dirigida a la liberación de las condiciones de opresión que aún presentan las realidades musicales costarricenses.
\end{abstract}

Palabras clave: Pedagogía crítica de la música, descolonización cultural, identidad musical costarricense, transformación de realidades, pedagogía de la liberación.

\begin{abstract}
This text aims at generating a critical review of the pedagogical model that has prevailed in Costa Rica for music education, especially since the so-called cultural reform
\end{abstract}

\section{(c) (1) $\odot \Theta$}

http://dx.doi.org/10.15359/rep.esp-21.5

1 Académico de la Escuela de Música de la Universidad Nacional de Costa Rica y profesor de percusión del Ministerio de Educación Pública en el Conservatorio de Castella. Magíster en Educación con énfasis en Pedagogía Universitaria (UNA) y Licenciado en Música con énfasis en Ejecución y Enseñanza del Instrumento: Percusión (UNA). 
in the early 1970's. In the search of alternative educational models, these reflections take stand from a critical perspective to propose a pedagogical epistemology free from the oppressive conditions still found in the Costa Rican music field.

Keywords: Critical pedagogy of music, cultural decolonization, Costa Rican music identity, transformation of realities, pedagogy of liberation.

\section{Introducción}

$\mathrm{H}$ ablar de pedagogía e intentar una o varias definiciones del término supone, necesariamente, una toma de posición. La perspectiva pedagógica y lo que pretenden los procesos educativos llevados a cabo no pueden desarrollarse desde la neutralidad, tampoco es posible sin tomar en cuenta el universo material que existe más allá del mundo de los contenidos disciplinares ${ }^{2}$, ni en ignorancia de que el conocimiento es un acto que de alguna manera conlleva al poder.

Independientemente de la conciencia que se tenga sobre lo anterior, es un hecho que debido a la "educabilidad" intrínseca en los seres humanos (Baquero, 2003), en todos los procesos educativos se llevan a cabo aprendizajes más allá del ámbito disciplinar que, para bien o para mal, transforman a las personas, principalmente, orientando su ideología y comportamiento y afectando su concepción de sí mismos y la manera como viven las relaciones interpersonales.

Entonces, se comparte la idea de que la educación "es el proceso de influencias que determinan o transforman el modo de ser, pensar, sentir y actuar de los seres humanos" (Aldana, 2011, p. 54). Desde esta visión, los contenidos disciplinares resultan muy provechosos, pero insuficientes per se para determinar una educación responsable con la vida, cuya labor no depende exclusivamente de las familias o de las escuelas primarias y secundarias, tampoco de las escuelas de estudios generales en el caso de la educación superior; cada proceso educativo es una "influencia” y debe estar comprometido con la orientación de sus

2 Por este nombre siempre se hace referencia a los contenidos que competen a los diversos objetos de estudio, principalmente, se utilizará más adelante para referirse a los contenidos propios de la disciplina de la música (teoría, técnica, ejecución, interpretación musical, etc.). 
contenidos hacia un fin mayor que solo el hecho de acumular conocimiento, entendiendo la educación como un todo permanente.

Es por esto que, para abordar la pedagogía de la música desde una postura crítica, resulta necesario que, de entrada, se reconozca que la educación musical, en cualquiera de sus enfoques y áreas especializadas, responde de igual manera a un proceso por el cual quienes educan en música, además de crecer en conocimiento teórico, técnico y experimental en la música, deben de desarrollar herramientas críticas, saberes y valores que les permitan acercarse al conocimiento de su propia realidad y la que les rodea. Aprender a leer música ${ }^{3}$ no es un proceso que trae consigo el descubrimiento de maneras para saber leer la realidad de forma crítica; es decir, no por sí, sin algún esfuerzo o pretensión pedagógica adicional que lleve a ello.

Por esta razón es que, sin perder de vista la responsabilidad que conlleva el conocimiento y dominio a fondo de los contenidos disciplinares musicales, así como la indagación de mecanismos didácticos para la mediación pedagógica de estos - puntos de partida indiscutibles para el buen ejercicio docente-, es determinante que los diversos cuerpos académicos de las disciplinas musicales se asienten también como corresponsables de procurar la búsqueda de una educación ética y estética que contemple la justicia social como fin. En ella, resulta insoslayable apartar la consideración de la dimensión política de la educación y su intencionalidad, que toma sentido una vez contextualizada dentro de un marco sociohistórico en concreto (Torres, 2005).

Para Torres (2005), la intencionalidad política de los procesos educativos tiende a oscilar entre dos polos discursivos opuestos: uno, defiende la educación como vía para paliar y atender las disfunciones que afectan la sostenibilidad del modelo socioeconómico y cultural vigente, y otro, sustenta que la educación es el brazo para llevar a cabo las transformaciones necesarias de las relaciones políticas, económicas y sociales desde las que se rigen las sociedades. De esta manera, se asume que en el primer caso prevalece la adaptación de los procesos educativos al sistema imperante, en donde la educación es el medio para conocer la ideología dominante y aprender a desenvolverse en ella. Desde esta visión, la realidad en la que se vive está determinada y es invariable. No se tiene posibilidad alguna de transformarla.

3 Con esto, se alude también a todo el saber técnico/instrumental de la música. 
Por el contrario, el otro extremo propone que la realidad sí puede ser transformada y que el vehículo es una educación cuyo objetivo es brindar las herramientas necesarias para lograrlo. Esa educación debe ser insistente en el conocimiento de la propia realidad desde una visión crítica, así como en el reconocimiento de sí como productos de esta misma, en aras de pasar a ser sujetos constructores del contexto contemporáneo (Aldana, 2011). Dicho esto último, podría afirmarse que es en esa dirección -la de crear conocimiento a través de la "concientización" (Freire, 2005)- en la que este trabajo pretende generar un acercamiento hacia diversos planos de la realidad musical costarricense, al intentar evidenciar algunas injusticias e investigar sus causas, para determinar el papel que podría realizar la pedagogía musical en cuanto se asume su poder transformativo.

En dicha finalidad, este trabajo se apoya principalmente de dos pilares, puntos de partida epistemológicos de esta propuesta: "la pedagogía crítica, la filosofía latinoamericana" en su vertiente liberadora y la "Interculturalidad" como sustento de una educación intercultural. El acercamiento a los principales enunciados de estas teorías permite pensar la educación de cualquier disciplina -en la que se incluye a la música- como el medio por el cual las sociedades logran alcanzar un estado superior de bienestar, en términos de una equidad social, económica y epistémica mediante la emancipación de los sujetos oprimidos (Dussel, 2015; Fornet-Betancourt, 2006; Freire, 2005; Santos, 2009).

Acorde con este punto de partida, surgen algunas interrogantes, eje transversal que atravesarán los apartados a desarrollarse a continuación: ¿qué se entiende por la realidad musical costarricense?, ¿quién es el sujeto oprimido en la música?, ¿es posible aportar a la emancipación social desde las disciplinas musicales?, y de ser afirmativo: ¿cómo materializar dichos aportes desde una educación superior musical comprometida con la formación crítica? Además, ¿qué sería una educación musical crítica, transformadora o que opte por la interculturalidad?

Con el fin de intentar el desarrollo de una propuesta a partir de estas preguntas, en el primer apartado de este trabajo se realiza un análisis epistemológico de la pedagogía de la música costarricense, cuya investigación, necesariamente, lleva a tomar en cuenta un contexto geopolítico más amplio, en el cual se hayan similitudes en las realidades del caso de Costa Rica con las de otros países latinoamericanos. Para dicho análisis, se tomará en cuenta no solo la dimensión objetiva 
de la música, sino, particularmente, su dimensión subjetiva, en la búsqueda de una reconexión entre la música y sus connotaciones dentro una visión cultural semiótica.

Primeramente, se intentará determinar a cuáles estructuras primarias obedecen los modelos educativos que llegaron a América Latina, y cómo siguen estando presentes en la educación musical costarricense. Luego, se evidenciará cómo han perpetuado el desarrollo de estos modelos -desde el ámbito musical- las cadenas de opresión que viven ciertas culturas en Latinoamérica desde tiempos de la colonia.

A raíz del análisis efectuado en la primera sección, se pasará a un segundo que desarrolla una propuesta pedagógica que, basada en la visión transformadora de la educación que propone la "pedagogía crítica", pretende generar procesos reflexivos constantes y críticos articulados dentro de la misma vivencia educativa en las aulas, para establecer, por medio de una verdadera praxis pedagógica, las condiciones necesarias para el rompimiento de las prácticas opresivas que continúan inmersas en la pedagogía musical costarricense.

\section{Reflexiones en torno a la revisión del aspecto epistemológico de la pedagogía de la música costarricense}

\section{Similitudes entre los puntos de partida de la escuela tradicio-} nal y el conservatorio de música

En la antigüedad, la pedagogía estaba asociada con la búsqueda de la virtud (el bien), y se le conocía con el nombre de "paideia" (Jaeger, 2001). El fin último de la "paideia" consistía en la transformación del sujeto en un individuo libre. Esta liberación se relacionaba con el alcance de la virtud, y procedía desde la acción del propio sujeto; es decir, desde su compromiso y voluntad por alcanzarla (Quiceno, 2014). Esta idea conllevó a un ideal de perfección humana que marcó la educación europea en la Edad Media y a principios de la modernidad, hasta que Rousseau estableció una línea diferente en donde la búsqueda de la perfección humana es puesta duda al considerársela una abstracción que deja de lado la actividad práctica del ser humano ${ }^{4}$ (Château, 2017).

4 Cuestión que radicalizarán pensadores como Dewey y Montessori -desde epistemologías distintas- Ambos consideran que el aprendizaje del ser humano nunca puede separarse de la teoría y la práctica; a lo que los marxistas le llamarán praxis. 
Según Quiceno (2014), con la expansión del cristianismo ${ }^{5}$ y posteriormente, el desarrollo de la modernidad ${ }^{6}$, la educación como vía para alcanzar la virtud pasó de ser el "despertar" de la conciencia individual mediante la interacción con el maestro, a convertirse en un medio de adoctrinamiento "necesario" para reproducir las políticas estatales, los modos de producción, las leyes y las doctrinas morales:

Conducir reemplazó la preocupación, el cuidado de sí y el conocimiento de sí, propios de la cultura antigua. Por conducir se entendió la domesticación y adaptación a los valores de la modernidad escolar y educativa, y sus representantes, el Estado, la Iglesia, la administración y la teología. (p. 33)

Es decir, la búsqueda de la virtud se aleja de su trasfondo ético y problematizador para convertirse en el camino conductor y proveedor de respuestas y técnicas que están determinadas por "el poder y la economía". La modernidad se conforma como fenómeno ideológico y estructural -o un ideario-, estableciendo lineamientos o respuestas "enlatadas" prácticamente, en todos los campos de la vida humana del hemisferio occidental. Este conjunto de respuestas, tomadas por verdades, constituyen lo que Torres (2005) llama "la ideología dominante"acude o crea, a su vez, un aparato difusor denominado escuela, y lo utiliza para legitimarse ante las masas, procurando que interioricen la dominación mediante la figura de la ciudadanía y la democracia. Así, los monasterios que fueron lugar para el aprendizaje de la doctrina cristiana dieron espacio a la institucionalización de la educación secular de corte burguesa y liberal, bajo el concepto de "escuela" y de "Estado" o de sociedades emergentes. Aquí, primero, la disciplina externa y luego, el autocontrol se convierten en los dispositivos del poder por excelencia (Foucault, 2000).

5 Haciendo referencia al cristianismo institucionalizado que se da a partir de la conversión de Constantino, y que se diferencia radicalmente del anterior, el cristianismo primitivo.

6 Ethos ideológico, cultural, económico y hegemónico europeo, centrado en la razón como absoluto universal, simplificando y despreciando los saberes y sentires que no responden a ese universo simbólico. La modernidad seculariza la naturaleza y la determina como un objeto, ajeno, lejano, medible y externo. Es de corte antropocéntrico y cientificista, basado en la totalización de la cultura nortecéntrica (eurocentrismo) en la (re)producción, especialmente, del modelo económico capitalista (Gómez, 2016). 
Siempre dentro de la modernidad, durante la revolución burguesa de principios del siglo XIX, un hecho que resultó clave en el triunfo del proyecto de escolarización, fue el surgimiento y proliferación de las escuelas normales auspiciadas por el Estado para la formación docente según los valores del nuevo orden liberal (Escolano, 1982), todo esto bajo un modelo pedagógico centralizado en la "instrucción": el docente era instruido para reproducir la instrucción a sus alumnos; aunque, también deben reconocerse algunos esfuerzos por salirse de esa línea como por ejemplo en Montessori, Declory, Dewey (Château, 2017); y en Costa Rica, Dengo, Carvajal, entre otros (Mora et al., 2004).

Producto de su gran efectividad, la "escuela elemental tradicional" como institución educativa de la disciplina y el control, así como las escuelas normales para la capacitación docente, se comenzaron a expandir de Prusia y Francia hacia todo el resto de Europa, llegando a los Estados Unidos, y, posteriormente, a América Latina. Consigo trajeron más que una metodología y visión educativa; para Pineau (2001), la escuela, además de ser el aparato de inculcación ideológica de las clases dominantes, marcó con su llegada la imposición definitiva de la cultura occidental como cultura hegemónica dentro y fuera de Europa.

Como parte importante del sustento epistemológico que sirvió para dar sostén a la institucionalización de la escuela, resalta la figura de Immanuel Kant. Para Kant, la educación es el camino para desprenderse de la naturaleza e introducirse en la cultura, ${ }^{7}$ entendida como acervo, formalidad y abstracción (Pineau, 2001); la visión kantiana de cultura responde a una monovisión del concepto que estaba determinado por el proceso de formación de la "nueva civilización moderna". De esta manera, todo lo que no esté civilizado representa la "barbarie" y debe ser transformado en pos de lograr ciudadanos civilizados y obedientes (Gómez, 2016). Es decir, la virtud, en Kant es la obediencia, pues para él conduce a la libertad del ser humano. Dicho de otra forma, para Kant, a los pueblos, si quieren llegar a ser libres, no les queda otra salida más que obedecer, ya que obedecer es lo que convierte a las personas en buenas ciudadanas. (Kant, 2012). Esta idea se problematizará más adelante desde la perspectiva de la pedagogía crítica.

7 Planteamiento que es refutado fuertemente por la teoría sociohistórico cultural, principalmente por Vygotski, ya que no considera posible que el aprendizaje -consciente o inconscientepueda ser separado de la dimensión histórico cultural (Vygotski, 2015). 
Hasta aquí, se ha planteado un breve acercamiento que permite ver con más claridad el contexto donde nace la escuela tradicional en Europa, y algunos fundamentos que hicieron que fuera instaurada como la herramienta para construir una sociedad moderna con hambre de "progreso". Una nueva civilización que no se desprende de sus prácticas colonialistas y hegemónicas, y que armada de la razón instrumental y un desarrollo cientificista e individualista, tendrá un gran impacto en la formación de los Estados latinoamericanos, incluyendo el Estado costarricense y sus políticas culturales.

Al hacer una comparación, se encuentra que, en el campo de la música, la escuela moderna también institucionalizó este saber y lo transmitió de forma doctrinaria. De esta manera, se piensa que, así como la escuela tradicional fue el aparato institucional ad hoc para la transmisión e imposición del ideario de la modernidad, el conservatorio de música jugó un papel similar en la institucionalización del saber disciplinado de la música, y fue muy importante en el desarrollo del contenido musical que se impuso desde la época moderna, ya que dicho contenido estaba dentro de la visión ideológica de la modernidad.

En sus inicios, el conservatorio de música nace en la Italia del Renacimiento como una especie de albergue infantil (ospedale) que procuraba mitigar la pobreza y el hambre de muchos niños que por diversas razones habían quedado huérfanos, mientras que se les enseñaba un oficio, entre ellos canto o la ejecución de un instrumento musical, para que pudieran sobrevivir por sí mismos y ser útiles a la sociedad (Aguirre, 2005; Pignatelli, 2016). Primeramente, estarán muy ligados a la vida de los monasterios y los conventos, con un modelo pedagógico escolástico para la enseñanza, y su misión abocada a la preservación de textos musicales y formas limitadas para la composición de estos mismos. En ese sentido, Florimo (1969, según se cita en Pignatelli, 2016) apunta lo siguiente:

El término conservatorio llegó a significar, finalmente, la función de asistencia social de "conservar" a las poblaciones más jóvenes y desvalidas de los peligros morales propios del abandono y por extensión, de las funciones asumidas por la institución, la conservación del legado de la música sacra a través de la enseñanza, de la labor de los copistas, del resguardo físico de los repertorios. (p. 19) 
A saber, el conservatorio de música fue una pieza clave para la Iglesia en su misión de custodiar el elemento cultural de los pueblos para el servicio de sus propias actividades (Pignatelli, 2016). De esta manera, el desarrollo de las diversas técnicas musicales y el componente experimental estaban dominados por la Iglesia católica, luego fueron también asumidos por la Reforma protestante y sus seguidores. En los siglos XVII y XVIII, la música en América Latina la impuso la Iglesia católica, siendo la misma de corte sacra y coral, dominada por los coros. Esa música estaba a cargo especialmente de los monasterios y las iglesias catedralicias o centrales, la música predominante venía de España y de Italia. Es a partir del siglo XIX que se da una fuerte influencia de otros países europeos, como Alemania, mediante el conservatorio, que como se señaló, se convirtió en un lugar estructurado y metódico para enseñar "música culta" mediante la lectura técnica y las transcripciones musicales, la técnica para tocar adecuadamente los instrumentos y el canto, y la formación de agrupaciones occidentales como las orquestas europeas. En general, se academiza la música considerándola una técnica en sí misma (Nasif, 2017).

En el caso de Costa Rica, la situación no es diferente al resto de Latinoamérica. Prevalece la imposición de la música sacra, y luego la música secular "clásica", en las cuales la herencia del conservatorio también juega un rol importante en ese proceso de erudición musical que se concentró a partir del siglo XIX en la oligarquía gobernante o en la burguesía en general, pues el alto costo de los instrumentos musicales -tal es el caso del piano-y la dificultad para acceder a este conocimiento imposibilitaban la democratización de ese saber (Nasif, 2017; Rojas, 2015).

Así las cosas, es importante comprender que al igual que la escuela tradicional, el conservatorio de música nace dentro del contexto de la modernidad, por tanto, es contenedor de su ideología. Dicho más claramente, ambos - escuela tradicional y conservatorio- son productos nacidos y utilizados para reproducir la ideología burguesa que se ha impuesto hegemónicamente. En virtud de ello, si la "música clásica" representa la estética cultural de la civilización a la cual apuntaba Kant, todo lo opuesto a esta música representaría -para la modernidad- la "barbarie"; la naturaleza a la cual se debe renunciar

8 Término de uso frecuente para referir a la música asociada con la cultura del Conservatorio o la Academia. Para dichos efectos, abarca un ámbito musical estilístico más grande que solo su referencia real hacia el período clásico del siglo XVIII. 
para proseguir el camino hacia "el progreso", así el conservatorio es un lugar ideal para implementar la civilización mediante la música formal y técnica, "culta o clásica".

En resumen, este planteamiento moderno de carácter monológico, presente desde la colonia, ocasionó la presencia de un discurso discriminador por parte de las élites sociales. Ellas veían de manera peyorativa a las otras formas musicales autóctonas por ser contenedoras de raíces africanas e indígenas (Monge, 2017) ${ }^{9}$. Ese rechazo se agravó con la constitución de los estados nacionales, quienes se pliegan a criterios modernos o formalistas de la estética kantiana que justifican ese desdén hacia esta que denominaremos: "la otra música"10.

A pesar de que América Latina ha sido el escenario físico de innumerables manifestaciones culturales a nivel regional de cada zona geográfica del continente, en las que la música ha jugado un papel preponderante en la formación de identidades sonoras autóctonas, las escuelas de música de educación superior costarricenses han permanecido renuentes a la incorporación de contenidos que no estén ligados a la tradición clásica europea, o que no hayan derivado de la matriz del conservatorio. Pese a lo anterior, se deben reconocer múltiples esfuerzos ya realizados, y otros en proceso, para ir superando el carácter peyorativo que la academia le ha dado a la música popular y a la folklórica de raíces indígenas-africanas. Sin embargo, aún nuestros programas y planes de estudios, y gran parte de la gestión curricular en general, continúan estando bajo la sombra "blancuzca" de un conservatorio de música hegemónico, moderno y colonizador.

\section{Detrás de la "blancura" uniforme de los cánones musicales acadé- micos: El caso costarricense}

Este segundo subtítulo gira en torno a la problematización del concepto de "creación de una cultura superior", alguna vez utilizado por el expresidente de la República José Figueres Ferrer para referirse a la necesidad de emprender una política cultural abocada al acercamiento del

9 Monge (2017) realiza un profundo y valioso análisis desde múltiples perspectivas acerca de la invisibilización que han sufrido las raíces africanas presentes en la música de la región centroamericana, al tiempo que aporta mucho material bibliográfico que considera un enorme punto de partida para la problematización de estas temáticas.

10 No solo por ser diferente, sino por pertenecer al otro ser, a la dimensión del sujeto excluido de la sociedad referida por Levinas en Dussel (2015). 
pueblo costarricense con la "música clásica"11, como un medio para la formación de una sociedad más civilizada (Cuevas, 1996; Rojas, 2015).

Para iniciar, Cuevas (1996) expone que antes de la década de 1970 existieron varios intentos para formalizar el desarrollo de la música clásica en Costa Rica, así como todas las llamadas "Bellas Artes", pero será hasta 1971, con la creación del Ministerio de Cultura, Juventud y Deportes -impulsado por Guido Sáenz, Alberto Cañas y el mismo José Figueres-que fue posible la materialización de los primeros y más significativos resultados en esa línea: la reorganización de la Orquesta Sinfónica Nacional (OSN) -acción que supuso la destitución de la mayoría de los músicos nacionales quienes fueron sustituidos por músicos extranjeros, principalmente estadounidenses y europeos-, la creación del Programa Juvenil de la Sinfónica Nacional -instruido por los músicos extranjeros de la OSN-, la formación de la Orquesta Sinfónica Juvenil y el inicio de los conciertos de extensión cultural para acercar al pueblo costarricense al deleite de conciertos de "música culta" ejecutada a un gran nivel.

Al analizar este discurso que encierra la justificación del desarrollo de prácticas musicales eurocentristas como parte de la metodología para apuntar hacia un estado de "cultura superior", Rojas (2015), atinadamente señala que "en vista de que existe una 'cultura superior' debe existir necesariamente una 'cultura inferior' frente a la cual realizar el contraste" (Rojas, 2015, p. 171). Ciertamente, este señalamiento indica la presencia de un verticalismo sociocultural disyuntivo entre lo "superior e inferior", cuya relación hegemónica ha provocado la invalidez de lo referente a la "cultura inferior" a partir de criterios científicos occidentales de pretensión universal; estos, aclara Fornet-'Betancourt (2006), no son falsos “por buscar lo universal ni por ofrecer referencias para la universalidad de lo humano sino por la extrapolación que de su peculiaridad ha hecho" (p. 57).

Nuevamente, se encuentra ante una dialéctica entre lo "civilizado" y la "barbarie". Una fijación por la utopía "modernista" representada en la promesa del progreso de la humanidad, que siente la necesidad de "erradicar la barbarie" por considerarla ausente de conocimiento verdadero y fuente del retraso cultural y económico (Gómez, 2016).

11 Privilegio que era casi exclusivo de la burguesía costarricense debido a los altos costos para acceder a los espectáculos del Teatro Nacional, códigos de vestimenta, entre otros filtros. 
Esa pretensión occidental por universalizar un único conocimiento válido conlleva consecuentemente a la descalificación a priori de otras formas de conocimiento que se asocian con la "cultura inferior" referida por Rojas (2015). En línea con esto, Santos (2009) -desde la filosofía decolonial- describe esa dimensión excluyente como un "epistemicidio"; y añade que el "pensamiento occidental moderno" es un "pensamiento abismal" que divide la realidad social en dos universos opuestos: "La división es tal que el 'otro lado de la línea' desaparece como realidad, se convierte en no existente, y de hecho es producido como no-existente. No-existente significa no existir en ninguna forma relevante o comprensible de ser" (Santos, 2009, p. 160). Es lo que Fanon denominó la línea del "no Ser" (Fanon, 2007).

En consecuencia con lo anterior, podría señalarse que las políticas culturales costarricenses desarrolladas a partir del cambio de paradigma surgido en la década de 1970 han contribuido a acrecentar la brecha entre el universo de la tradición occidental - correspondiente a la "música clásica"- y su opuesto "no-existente" representado en el universo de la música popular y de raíces folklóricas, cuya matriz no obedece a la separación kantiana entre naturaleza y cultura. Monge (2017), problematiza esta dicotomía entre la música "culta y popular", y señala la necesidad de superar la connotación de "formalidad e informalidad" que respectivamente está implícita detrás de los conceptos anteriores, ya que "cubren de oscuridad epistemológica las músicas contemporáneas y banalizan la compleja semiosis del evento-suceso musical" (Monge, 2017, p. 99).

Con base en este principio dicotómico entre lo visible y lo invisible, lo válido y no válido, lo que es y lo que no es, lo que encamina hacia el "progreso" o retorna a la "barbarie", es que se han constituido una gran mayoría de los modelos pedagógicos para la educación musical superior en Costa Rica; y por años, han mantenido lejos de su currículo oficial los contenidos que "ennegrezcan" o "indigenicen" la "pureza" de la herencia musical occidental. De esta manera, se continúan dificultando los esfuerzos por intentar entablar una discusión seria acerca del problema de la identidad cultural, cuyo objetivo debería apuntar hacia la búsqueda de una identidad musical costarricense que contemple la herencia de las raíces afro-indo-americanas, pero sin caer en esencialismos, pues la fetichización de estas culturas folklóricas también es 
un obstáculo para una epistemología y musicología consistentes en el abordaje de estas temáticas culturales (Carvalho, 2003; Monge, 2017).

En este punto, se torna importante señalar que, si bien es cierto, este rechazo estético y político hacia la música popular y de raíces folklóricas ha empobrecido la enseñanza de la música en Costa Rica limitándola a una monovisión eurocentrista, el sujeto de esta, el de la "otra música", permanece -en la mayoría de los casos- aún desacreditado por las escuelas, y por ende, apartado o desligado de la vida universitaria. Esto imposibilita, o al menos entorpece, un intercambio de saberes, visiones y sentires que, además de enriquecer los aprendizajes musicales de ambos sujetos (el "académico" y el "popular"), podrían aproximar el panorama hacia una experiencia más intercultural mediada por la música, intentando superar meramente el plano multicultural $^{12}$. Es decir, a pesar del conocimiento que se tiene de algunos esfuerzos académicos y administrativos que históricamente han intentado liberar a la enseñanza musical del modelo hegemónico occidental, luchando por el reconocimiento de la Otra música, estos esfuerzos resultan insuficientes, al menos desde una visión ética intercultural, si no se desarrollan a partir de procesos dialógicos y horizontales que integren la dimensión subjetiva de los músicos y creadores musicales de la "otra música", en plena consideración de sus realidades sociohistóricas.

En esa misma línea, Carvalho (2003) evidencia un sesgo que gira en torno a la tendencia objetivista de estudios culturales, musicológicos y etnomusicológicos:

Y acá el primer punto teórico importante es que se separa la cultura de la sociedad. Han surgido varios estudios etnomusicológicos en los cuales se habla de la música, de la cultura, de los músicos, pero no se habla de los dilemas de la sociedad. ¿Por qué? Porque nos interesa la música afro, pero no nos interesamos por la pobreza de los músicos afro-americanos". (p. 7)

Es por esto que la propuesta pedagógica que se pretende ofrecer como punto de partida en este trabajo, no aspira a la integración de la

12 A diferencia de la multiculturalidad, cuya línea se agota en el pleno reconocimiento del otro, la interculturalidad se interesa por el establecimiento de un enlace dialógico y horizontal entre las diferentes culturas, abriendo espacio para el desarrollo de valores como la empatía y solidaridad por el otro. 
"otra música" como un objeto descontextualizado de la cultura ni la sociedad, es decir, únicamente como un fin en sí misma; potenciar "lo propio" nos debería de implicar en una búsqueda de alternativas estructurales que ataquen el desequilibrio social ocasionado por las mismas condiciones de opresión en las que se ha desarrollado la enseñanza musical costarricense, pues tal y como señala Fornet-Betancourt (2006):

El desprecio de las contextualidades, para cuya superación -dicho sea de paso- no basta simplemente la inocente vuelta fenomenológica a las cosas mismas porque se trata de descubrir también las estructuras injustas que las "ocultan", conlleva naturalmente el desprecio de las encarnaciones de la misma condición humana. (p. 27)

De ahí que una epistemología de la pedagogía de la música universitaria no podría ocuparse únicamente del objeto (la música), ignorando la carga ética que implica asumir el fin de la pedagogía en su dimensión transformadora de las realidades. Ante ese panorama, la epistemología de la pedagogía musical universitaria ha de apostar por la integralidad del ser humano, donde los valores éticos, estéticos y políticos jueguen un papel central para superar la fragmentación de la epistemología moderna que separa, mide, clasifica y divide hasta el absurdo para con ello vigilar y controlar los procesos sociales mediante el artificio de la ciencia reducida a su expresión positivista.

A continuación, se verán algunos elementos de una posible epistemología universitaria de la pedagogía musical crítica, integral y comprometida con la transformación social o con el bienestar pleno del sujeto humano y de la naturaleza misma.

\section{La enseñanza musical costarricense en la praxis desde la visión de la pedagogía descolonizadora latinoamericana}

Ante las diversas situaciones expuestas en la primera parte de este trabajo, se considera a la "pedagogía crítica" como una vía alternativa para una epistemología de la educación musical costarricense, no solo en aras de mejorar las prácticas educativas en el contexto de la pedagogía de la música, sino desde una visión política que procura la "descolonización" de los aspectos culturales eurocentristas que han condicionado a los estudios musicales en Costa Rica, y que además aún 
mantienen vivas algunas relaciones de opresión que históricamente no han podido ser superadas. De esta manera, se considera que la música, además de tener un gran valor estético, es un objeto poderosísimo para la "emancipación" latinoamericana.

Precisamente, la "pedagogía crítica" constituye un evento político liberador que intenta desnudar la falsa pretensión de neutralidad de la educación (Freire y Shor, 2014). Su intención es evidenciar que la educación tradicional o "bancaria"13, ha ocultado la relación indisociable entre los contenidos y la intencionalidad política para la cual se trasmiten los mismos. Esto último ha ayudado a que sea posible disfrazar la subsistencia de condiciones de opresión que han establecido las clases sociales hegemónicas para la preservación del status quo (Freire, 2005). Es por eso que para emprender el camino de la educación musical desde la perspectiva de la "pedagogía crítica", no es posible contemplar a la pedagogía como un conjunto de estrategias metodológicas, evaluativas, didácticas o curriculare ${ }^{14}$ que, aunque ciertamente están unidas a ella, es necesario que primero se asuma un compromiso por la transformación de las condiciones de opresión que viven las realidades latinoamericanas. La pedagogía crítica musical es entonces una propuesta que contemplaría la dimensión política, ética, estética, intercultural y axiológica de la realidad musical costarricense, y por medio de la educación busca llevar a cabo las transformaciones necesarias en pos de construir nuevas realidades ecuménicas.

De este modo, el camino para la liberación es primeramente un camino de "concientización", de reconocimiento. Aprender a leer la realidad desde una mirada crítica es el primer estadio para trabajar en pos de la construcción de la propia realidad (Aldana, 2011; Freire, 2005). Como dicen Freire y Shor (2014): “¡Podemos luchar para ser libres precisamente porque sabemos que no lo somos! Por eso podemos pensar en la transformación" (p. 34). De ahí que el primer paso de este trabajo haya sido señalar que la realidad musical costarricense muestra relaciones de opresión que han sido representadas por el discurso dominante de la música "culta" o "clásica", y su imposición como vía para la creación de la

13 Concepto introducido por Freire (2005) a inicios de la década de 1970 con el cual pretende hacer referencia a los modelos educativos basados en el principio de transferencia del conocimiento. Su principal característica es que encierran en el fondo una intencionalidad por no alterar las estructuras que sostienen al modelo de producción vigente.

14 Visión reduccionista de la "educación bancaria". 
llamada "cultura superior" (Rojas, 2015); ahogando de esta manera la posibilidad de acercarse a la búsqueda de una identidad musical propia que involucre a los actores invisibilizados, quienes desde diversas manifestaciones continúan manteniendo viva su tradición musical.

De ahí que el desarrollo de una epistemología universitaria de la pedagogía crítica musical también debe contemplar necesariamente la dimensión de la alteridad. Dussel (2015) la describe de la siguiente manera:

Es la lucha por la afirmación del Otro como otro, no como lo mismo. No es la incorporación del excluido al orden jurídico vigente, sino la transformación analógica (analéctica) del orden jurídico, en el que los nuevos participantes cambian diacrónicamente las determinaciones funcionales de todos los antiguos participantes, construyendo un nuevo Estado de derecho que incluye la alteridad. (p. 70)

Este planteamiento de Dussel (2015) está muy relacionado con la búsqueda de una justicia intercultural que luche por el reconocimiento de las distintas cosmovisiones que han sido menospreciadas por consecuencia de un eurocentrismo dominante (Fornet-Betancourt, 2006), y es en esa sintonía que la educación musical costarricense debe entrar en razón de que su obstinación por el desarrollo del modelo pedagógico occidental como única alternativa "seria", ha provocado el rechazo de otras epistemologías en la enseñanza musical que ayuden a abrir la posibilidad de un "diálogo intercultural" que debe ser "transversal"; esto es que "debe partir de otro lugar que el mero diálogo entre los eruditos del mundo académico o institucionalmente dominante" (Dussel, 2015, p. 284).

Por tal razón, como parte de este proceso de apertura al diálogo, "la pedagogía crítica" busca romper con las relaciones de verticalidad que la "educación tradicional" ha creado entre profesores y estudiantes. En esa visión, la figura del profesor es "la que sabe", y la del estudiante "la que no sabe" (Freire, 2005, p. 80). Esta cualidad de la educación bancaria se centra en el principio de la transferencia del conocimiento. En ella, el educador es el encargado de "llenar" las mentes de sus estudiantes como si fueran un recipiente vacío. De esta manera, se dificulta la existencia de un interés genuino por parte del estudiantado hacia su proceso educativo, ya que la educación no se presenta como una vía para la transformación de sus realidades. Por eso, para Freire 
(2005), mientras existan procesos educativos que continúen aplicando una educación bancaria, se seguirá alargando el camino de la liberación. Dicho más claramente, y contextualizándolo al tema de este trabajo, hasta no superar las relaciones de verticalidad existentes en los procesos educativos de las escuelas universitarias de música que conlleven a la población estudiantil a involucrarse activamente en la construcción de su propia realidad, al tiempo que desarrollan una participación y un sentido de pertenencia hacia los contenidos que forman parte de su identidad, no será posible hablar de una liberación de la pedagogía musical costarricense.

Ahora bien, para emprender ese camino hacia la liberación, las escuelas de música de las universidades deben de iniciar un proceso reflexivo que re-signifique lo que entienden por docencia, investigación y extensión, utilizando para ello epistemologías que ayuden a brindar soporte para emancipar las prácticas llevadas a cabo dentro y fuera de sus aulas y cubículos. La docencia universitaria en la disciplina de la música debería abordarse desde una perspectiva dialógica que inicia por la "horizontalización" de los roles yuxtapuestos entre profesor y estudiante. Para esto, habría que empezar por desmitificar la conceptualización de la figura docente como profesional en la música, con condiciones de completud, autosuficiencia, poseción del conocimiento y de respuestas, determinante del camino y de la técnica; y al estudiantado como la única figura que aprende, que es -de entrada-ignorante y que además debe acogerse, sin problematización, a las respuestas que le son antepuestas durante su proceso.

Esta apuesta por entablar procesos dialógicos en las relaciones docente-estudiante ameritan necesariamente que exista una intensa fe en el otro ser. "La fe en los hombres es un dato a priori del diálogo", y a su vez, "la autosuficiencia es incompatible con el diálogo" (Freire, 2005, p. 110). En ese sentido, el individualismo que fomenta el modelo de educación musical occidentalizado, que apunta hacia la formación de la figura del solista autosuficiente, enturbia y obstaculiza el desarrollo de un sentido de necesidad comunitaria en las prácticas musicales. Esta ausencia en la pedagogía es, a la vez, un vacío en la ejecución musical, que se manifiesta en la dificultad de reaccionar ante las diversas eventualidades que suceden durante la práctica colectiva de ejecución musical. Educar para aplacar el ego no puede realizarse desde 
otra dimensión que no sea la horizontalidad, caso contrario estaríamos ante una contradicción.

Por otro lado, la población estudiantil debería de poder acceder al conocimiento y la práctica de la "otra música" desde la experiencia de sus verdaderos actores. En virtud de ello, los esfuerzos realizados desde la investigación por emprender la búsqueda de la identidad musical costarricense no pueden estar separados de la docencia ni de la extensión universitaria. El involucramiento estudiantil dentro de estas prácticas investigativas se convierte en el reto principal para una pedagogía liberadora. La liberación se materializa cuando el aprendizaje de estos nuevos saberes se lleva a cabo de una manera consciente, desde la acción y deseo del mismo alumnado por conocer y acercarse a estos saberes. En línea con esto, existen modelos investigativos, como la investigación acción participativa (IAP) o la sistematización de experiencias, que además de permitir un mayor involucramiento subjetivo multidimensional, su base epistemológica y metodológica responde a procesos más de horizontales y éticos que se consideran clave en la búsqueda por reconocimiento de los saberes excluidos ${ }^{15}$.

Finalmente, la extensión universitaria debe considerarse un intercambio de saberes, no la transmisión del saber universitario a las regiones periféricas. La estimulación y motivación docente debería preocuparse de que el estudiantado de las escuelas superiores de música sientan que realmente aprenden de los otros saberes, y que es un conocimiento valioso y necesario para su educación; en ese sentido, la conexión universitaria con las comunidades resulta fundamental para alimentar el espíritu material de la universidad y reconectarla con las realidades externas a sus campus. A su vez, las comunidades pueden verse favorecidas con las experiencias investigativas que surgen de las iniciativas académicas, especialmente, cuando asumen el poder transformativo de la investigación, como es el caso de la sistematización de experiencias. De esta manera, se estarían reforzando las situaciones norte-sur, existiendo una devolución de la palabra o saberes robados al alumnado y a la comunidad misma (D'Antoni et al. 2013, p. 33) y, con una mediación pedagógica crítica y comprometida con la

15 Por asuntos relacionados con la extensión de este trabajo no ampliaremos más detalladamente la importancia de la IAP y la Sistematización de Experiencias en el reconocimiento de la"otra música" y su sujeto olvidado. Pero se considera de carácter necesario la realización de una investigación que se aboque de lleno al tema. 
transformación, se revalora y resignifica el papel de sujetos completos e integrales que son en sí mismos la población estudiantil. Entonces, recapitulando, la pedagogía crítica aplicada en la pedagogía musical costarricense apelaría, primeramente, al reconocimiento e interés por los saberes de la música autóctona folklórica y popular ("la otra música"), y más allá que eso, representa la incorporación de su sujeto olvidado, rechazado o invisibilizado (músicos ejecutantes, compositores, arreglistas de la "otra música"). Segundo, abriría la posibilidad de emprender un camino hacia la valorización de lo "propio" en la música, hacia el intento por el rescate de la identidad musical costarricense, cuyo compromiso no esté en manos de un reducido grupo académico o de sujetos agentes políticos de la cultura, sino que a partir de un empoderamiento estudiantil y de profesionales en música y composición que el sistema ha constreñido, y de una concientización ciudadana encaminada hacia la liberación de los supuestos culturales impuestos, se puedan crear enlaces dialógicos que conlleven a contribuir en la búsqueda de la transformación de las realidades. Un aporte desde la música para continuar el camino hacia una verdadera democracia participativa, intercultural y ecuménica.

\section{Reflexiones finales}

La esencia del ideario de la modernidad y su discurso civilizatorio continúan estando muy presentes dentro de la cultura costarricense. Esto, consecuentemente, implica que la educación en general haya mantenido un sesgo hacia la reproducción de modelos importados de los países centrales que encaminan hacia una falsa realidad utópica de progreso y desarrollo prometida por la modernidad, ya que, en el fondo esta visión educativa, sigue ocultando sus prácticas colonialistas y hegemónicas en el ejercicio de su poder.

Ante esta situación, la educación musical no ha sido la excepción. No solo se ha mantenido bastante ensimismada y alejada de la realidad que vive la coyuntura social y cultural, sino que se ha naturalizado la invisibilización del Otro sujeto musical. Por eso, apelar a la incorporación de "la otra música" dentro del currículo oficial de las carreras universitarias es un importante paso para comenzar una descolonización de la enseñanza musical en Costa Rica que nos lleve a contemplar la música "con ojos no occidentalizados", sino propios. Sin embargo, esta construcción de "lo propio", debe ir paralela con la búsqueda de la 
liberación del sujeto oprimido de "la otra música". De otra manera, se estaría construyendo una falsa identidad musical, ya que no involucra a sus verdaderos actores. Además, se estaría superando el rechazo estético hacia el objeto (la otra música), pero no contempla la dimensión ética materializada en la lucha por el reconocimiento de la desigualdad y la aplicación de una justicia intercultural.

Concientizando esta problemática, la pedagogía crítica se inclina como una alternativa para establecer puentes dialógicos a través de la educación. La estimulación de valores como la empatía, la solidaridad por la otredad y la valorización de lo propio -sin apelar a nacionalismos-, son acciones determinantes para que la pedagogía liberadora trabaje en el empoderamiento estudiantil, para el involucramiento de esta población en la transformación constante y activa de sus realidades.

A su vez, en Costa Rica, la universidad pública se vislumbra como el medio que podría tener las mejores condiciones para alojar esta re-construcción de la pedagogía de la música costarricense, contemplativa de la alteridad y desarrolladora de una identidad en el saber musical. Con esto no se quiere decir que puedan existir otros esfuerzos individuales o colectivos de sectores estatales o privados que aporten en este desarrollo, pero sí consideramos que la tarea fuerte debe estar en manos de la universidad pública quien es el aparato institucional con los mejores recursos para llevarla a cabo, y cuya razón de ser carece de sentido si no está justificada en un accionar para superación de las condiciones de desigualdad social, económica y epistémica. De ahí que la protección de los recursos universitarios sea vital para que no se empañen los esfuerzos que apuntan hacia el mejoramiento de las sociedades, la construcción de mejores mundos posibles.

Por último, se quiere acotar que a pesar de la criticidad con la que se ha abordado la música clásica, esta propuesta no apela en ningún momento por un abandono del estudio riguroso de ese valioso conocimiento que encierra la música europea. La diferencia radica en la necesidad de que la educación musical costarricense rompa con el tratamiento absolutista que se le ha dado a esta tradición musical eurocentrista como el único y verdadero camino para la formación musical. En ese sentido, Dussel (2015) menciona:

No es la Modernidad la que le impone al intelectual crítico sus instrumentos; es el intelectual crítico el que controla, maneja 
la elección de los instrumentos modernos que le serán útiles para la reconstrucción crítica de su propia tradición, no como sustancia fija. (p. 287)

El estudio técnico musical debe dejar de contemplarse en la educación como un fin en sí mismo. Las herramientas técnicas heredadas del mundo de la música occidental deben contextualizarse y adaptarse a las necesidades musicales de la música latinoamericana, y propiamente, la costarricense. Como dijo Santos (2009), es "pensar el Sur como si no hubiese Norte" (p. 108); construir "lo nuestro" y desarrollarlo por cuenta propia. Para ello, se argumenta que la pedagogía es el camino, el medio y el comienzo de esa reconstrucción.

\section{Referencias}

Aguirre, M. (2005). Los conservatorios de música: Historias olvidadas. Correo del maestro, 9(104), 48-52.

Aldana, C. (2011). Pedagogía para nuestro tiempo. Enfoque vivencial para estudiantes. Piedra Santa.

Baquero, R. (2003). La educabilidad como problema político. Una mirada desde la psicología educacional. En C. Wainerman (Coordinadora), Seminario Permanente de Investigación de la Maestría en Educación de la UdeSA. Conferencia llevada a cabo el 23 de marzo de 2002 en la Universidad de San Andrés, Buenos Aires, Argentina. https://repositorio.udesa.edu.ar/jspui/bitstream $/ 10908 / 772 / 1 / \% 5 \mathrm{bP} \% 5 \mathrm{~d} \% 5 \mathrm{bW} \% 5 \mathrm{~d} \% 20 \mathrm{DT} 9-$ Baquero.pdf

Carvalho, J. (2003). La etnomusicología en tiempos de canibalismo musical. Una reflexión a partir de las tradiciones musicales afroamericanas. Trans. Revista Transcultural de Música, 7. https://www. sibetrans.com/trans/articulo/212/la-etnomusicologia-en-tiempos-de-canibalismo-musical-una-reflexion-a-partir-de-las-tradiciones-musicales-afroamericanas

Cuevas, R. (1996). El punto sobre la i: Políticas culturales en Costa Rica (1948-1990). MCJD.

Château, J. (2017). Los grandes pedagogos (2. ${ }^{\mathrm{a}}$ ed.). Fondo de Cultura Económica.

D’Antoni, M., Gómez, J., Gómez, L. y Soto, J. (2013). La escuela en cuestionamiento: Diálogos sobre la resistencia escolar en procesos pedagógicos emergentes. Arlekín. 
Dussel, E. (2015). Filosofias del Sur. Descolonización y transmodernidad. Akal.

Escolano, A. (1982). Las escuelas normales, siglo y medio de perspectiva histórica. Revista de Educación, 269, 55-76.

Fanon, F. (2007). Los condenados de la tierra (2. ${ }^{\mathrm{a}}$ ed.). Kolectivo Editorial Último Recurso.

Fornet-Betancourt, R. (2006). La interculturalidad a prueba. Concordia (Tomo 43). Mainz.

Foucault, M. (2000). Vigilar y castigar: Nacimiento de la prisión (30. ${ }^{\mathrm{a}}$ ed.). Siglo XXI.

Freire, P. (2005). Pedagogía del oprimido (55. a ed.). Siglo XXI.

Freire, P., Shor, I. (2014). Miedo y osadia: La cotidianidad del docente que se arriesga a practicar una pedagogía transformadora. Siglo XXI.

Gómez, J. (2016). Fundamentos pedagógico-filosóficos de las propuestas estatales de la "educación indígena" en Centroamérica: Estudio documental comparado de los casos de Guatemala y Costa Rica durante la primera década del siglo XXI [tesis doctoral no publicada]. Universidaad Nacional.

Jaeger, W. (2001). Paideia: Los ideales de la cultura griega. Fondo de Cultura Económica.

Kant, I. (2012). Contestación a la pregunta: ¿Qué es la ilustración? Taurus.

Monge, L. (2017). Raices africanas presentes en la obra musical de Luis Enrique Mejía Godoy, Walter Ferguson y Rubén Blades. Alma Mater.

Mora, G., Monge, C., Rubio, C., Ordónez, J. y Cordero, G. (2004). Grandes maestros costarricenses. Cuadernos Pedagógicos 1. Editorial de la Universidad de Costa Rica.

Nasif, Y. (2017). Hegemonía, poder y cultura en la educación musical y artística en Colombia. En J. Amador (Ed.), Cultura, saber y poder en Colombia: Diálogos entre estudios culturales y pedagogías críticas (pp. 113-139). Universidad Distrital Francisco José de Caldas.

Pignatelli, N. (2016). La función pedagógica del profesor de piano en grado superior ante el miedo escénico de los alumnos [tesis doctoral no publicada]. Universidad Complutense de Madrid. https:// eprints.ucm.es/40581/1/T38123.pdf 
Pineau, P. (2001). ¿Por qué triunfó la escuela? o la modernidad dijo: "Esto es educación" y la escuela respondió: "Yo me ocupo". En P. Pineau, I. Dussel y M. Caruso (Eds.), La escuela como máquina de educar: tres escritos sobre un proyecto de la modernidad (pp. 27-52). Paidós

Quiceno, H. (2014). Epistemología de la pedagogía (2.a ed.). Ediciones Pedagogía y Educación.

Rojas, J. (2015). ¿Para qué carretas sin marimbas? Hacia una historia crítica de las prácticas de la música "clásica" en Costa Rica (1971-2011). Arlekín.

Santos, B. (2009). Una epistemología del sur: La reinvención del conocimiento y la emancipación social. Siglo XXI.

Torres, J. (2005). El currículum oculto. Ediciones Morata.

Vygotsky, L. (2015). Pensamiento y lenguaje. Arvato. 
